\title{
Modelling Mixing within the Dead Space of the Lung Improves Predictions of Functional Residual Capacity \\ Chris D Harrison ${ }^{\mathrm{a}}$, Phi Anh Phan ${ }^{\mathrm{b}}$, Cathy Zhang ${ }^{\mathrm{c} 2}$, Daniel Geer ${ }^{\mathrm{d}}$, Andrew D Farmery ${ }^{\mathrm{b}}$, Stephen J Payne ${ }^{a}$. \\ a Institute of Biomedical Engineering, Department of Engineering Science, University of Oxford, Old Road Campus Research Building, Roosevelt Drive, Oxford, OX3 $7 D Q, U K$. \\ ${ }^{b}$ Nuffield Division of Anaesthetics, Nuffield Department of Clinical Neurosciences, University of Oxford, John Radcliffe Hospital, Oxford, OX3 9DU, UK. \\ c New College, University of Oxford, Holywell Street, Oxford, OX1 3BN, UK. \\ ${ }^{d}$ The Queen's College, University of Oxford, High Street, Oxford, OX1 4AW, UK.
}

\footnotetext{
1 Present address: Power Networks Demonstration Centre, Department of Electronic and Electrical Engineering, University of Strathclyde, 62 Napier Road, Wardpark North, Cumbernauld, G68 OEF. 2Present address: GKT School of Medical Education, King's College London, London, SE1 9RT. (C)2017. This manuscript version is made available under the CC-BY-NC-ND 4.0 license http://creativecommons.org/licenses/by-nc-nd/4.0/
} 


\section{Abstract}

Routine estimation of functional residual capacity (FRC) in ventilated patients has been a long held goal, with many methods previously proposed, but none have been used in routine clinical practice. This paper proposes three models for determining FRC using the nitrous oxide concentration from the entire expired breath in order to improve the precision of the estimate.

Of the three models proposed, a dead space with two mixing compartments provided the best results, reducing the mean limits of agreement with the FRC measured by whole body plethysmography by up to $41 \%$. This moves away from traditional lung models, which do not account for mixing within the dead space. Compared to literature values for FRC, the results are similar to those obtained using helium dilution and better than the LUFU device (Dräger Medical, Lubeck, Germany), with significantly better limits of agreement compared to plethysmography.

\section{Keywords}

Lung function; Functional residual capacity; Mathematical model; Parameter estimation; Alveolar volume; Airway dead space; Nitrous oxide; Mechanical Ventilation. 


\section{Introduction}

Although there are several methods of routinely assessing lung function, they often require subject cooperation, are only suitable for use within a dedicated lung function laboratory or both (Clifton et al., 2013; Heinze et al., 2007). Therefore, routine monitoring of ventilated patients is not commonplace, despite $24 \%$ of patients starting ventilation with no signs of acute lung injury (ALI) going on to develop ventilator-associated lung injuries within the first five days (Gajic et al., 2004). Determining the optimum level of positive end expiration pressure (PEEP) within ventilated patients is controversial. Higher PEEP levels can help to reopen parts of the lung, recruiting alveolar units and reducing alveoli collapse, but there are several draw backs, including the potential inhibition of capillary blood flow (Dushianthan et al., 2011; Soni and Williams, 2008). Trials have shown clinical improvements when using higher PEEP within ALI patients, but in general there has been no improvement in mortality (Dushianthan et al., 2011; Rouby et al., 2013).

Imaging techniques have been used to assess the response to higher PEEP (Dushianthan et al., 2011; Rouby et al., 2013), but this is a discrete form of monitoring, rather than a continuous one, and is often impractical in ventilated patients (Schmidt, 2012). Selection of appropriate PEEP levels based on pressure-volume curve analysis or a patient's oxygenation level has been advocated, but uncertainties remain with regard to the best way to determine the optimum PEEP level (Miller et al., 2012; Schmidt, 2012; Soni and Williams, 2008).

FRC measurement to guide PEEP levels has been advocated for some time, but has not been used in routine clinical practice (Cortes and Marini, 2013; Hedenstierna, 1993; Rouby et al., 2013). Early methods relied on mass spectrometers (Gothard et al., 1980; Mitchell et al., 1982; Sivan et al., 1990; Williams et al., 1997), but they are bulky, temperamental and becoming harder to source (Arieli, 2010; Hahn, 1996; Horsley et al., 2014), so have not been used in clinical practice. More recently, several methods which do not use mass spectrometers have been proposed (Brewer et al., 2011; Olegård et al., 2005; Weismann et al., 2006), but further validation is needed before they are recommended for routine clinical use (Rouby et al., 2013).

All these methods use sidestream sampling to measure the gas concentration, which causes a delay that is difficult to correct (Bates et al., 1983; Farmery, 2008; Horsley et al., 2014). This results in a misalignment with the other measurement required by all methods (the air flow rate), causing errors in the FRC predictions (Farmery, 2008). The work presented here uses a prototype device that overcomes both issues by using a small mainstream gas analyser, making it more practical for point of care use.

(C2017. This manuscript version is made available under the CC-BY-NC-ND 4.0 license http://creativecommons.org/licenses/by-nc-nd/4.0/ 
Many methods have relied on a small number of observations per breath (Brewer et al., 2011; Gavaghan and Hahn, 1996; Gothard et al., 1980; Hahn, 1996; Hahn et al., 1993; Mitchell et al., 1982; Olegård et al., 2005; Weismann et al., 2006), for example each breath only yielding one data point: the end-expired concentration. Here methods that use the entire expired signal are presented, which may increase the information extracted from the data.

The aims of this paper is to present three possible models of the lung that can produce the entire expired concentration signal, define the best model for estimating the FRC and show this can be done using equipment that is practical for point of care use.

\section{Methods}

\subsection{Computational Models}

Three models of the lung were used (Figure 1), with the associated equations presented in Appendix A. Model 1 was based on the 'balloon on a straw' model of tidal breathing (Gavaghan and Hahn, 1996; Hahn and Farmery, 2003). This model assumes that no mixing occurs within the dead space, but in reality mixing will occur as gas diffuses and there will be areas of turbulent flow due to the branching structure of the lung. Two ways of modelling that mixing are proposed here; within Model 2 an additional mixing compartment is added at the mouth and Model 3 uses two mixing compartments.

The methods of determining FRC described in Section 1, involve varying the concentration of a tracer gas using a forcing function in order to extract information about the FRC, for example a step function in the case of wash-in/out techniques. Nitrous oxide was used in low concentrations because it is physiologically inert and sensors, which have proved effective in previous work, were readily available (Clifton et al., 2013; Farmery, 2008). The uptake and return of gas from the body must be considered, as nitrous oxide is a reasonably soluble gas (blood-gas partition coefficient 0.47). Previous work has shown that if a sinusoidal perturbation function is used, then (at equilibrium) the venous signal is sufficiently attenuated by the body compartment that it can be ignored without overly affecting lung parameter predictions (Gavaghan and Hahn, 1995). Thus a sinusoidal function was used rather than a step function, as the errors associated with a step function are likely to be large.

True equilibrium takes a considerable time (Williams et al., 1994). Thus the lung was brought to a fixed concentration over a period of between 60 s and 100 s and the model solved assuming a constant venous return concentration. A sensitivity analysis has shown that the errors in FRC associated with this assumption are in the order of $4 \%$ (Harrison, 2016).

(C)2017. This manuscript version is made available under the CC-BY-NC-ND 4.0 license http://creativecommons.org/licenses/by-nc-nd/4.0/ 
(a)

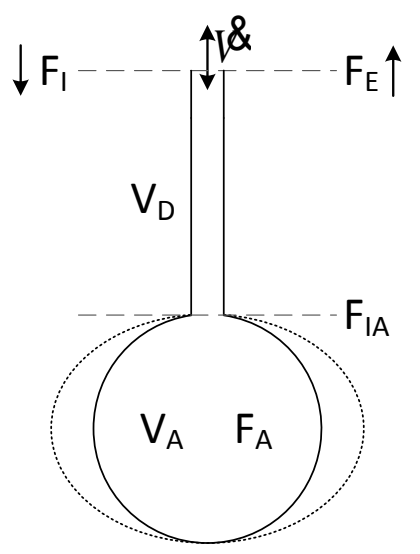

(b)

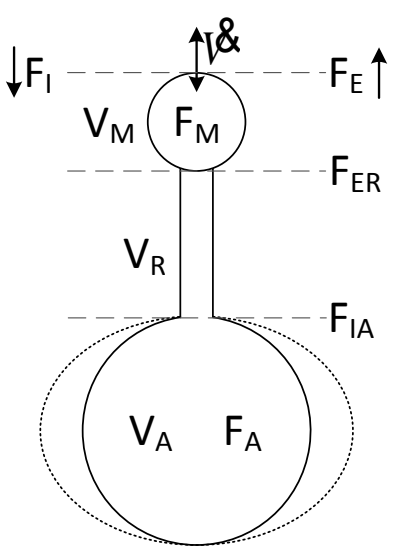

(c)

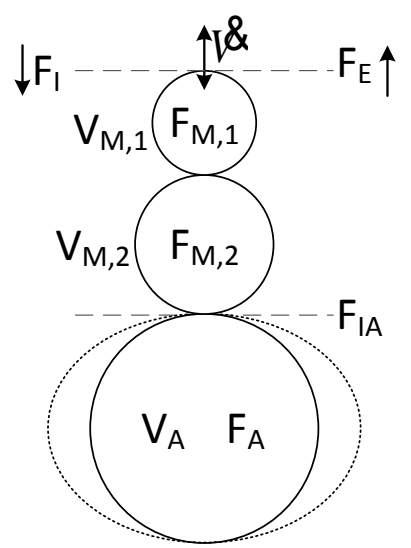

Figure 1 -Schematic diagram of the three models investigated: (a) Model 1, (b) Model 2 and (c) Model 3. All symbols are described in Appendix A.

\subsection{Parameter estimation}

A least squares approach was used to estimate the model parameters, with a genetic algorithm followed by the Nelder-Mead simplex used to minimise the root mean squared error between the model predictions and the data values (Belegundu and Chandrupatla, 2011; "Matlab R2014a documentation," 2014). This was found to be effective by Harrison (2016), with the genetic algorithm ensuring the global minimum is more likely to be found and the Nelder-Mead simplex ensuring a timely convergence. Both are non-derivative based methods so less prone to errors caused by the artefacts found in real data. The following parameters in the model were adjusted: the fixed dead space volumes $\left(V_{D}, V_{M}, V_{R}, V_{M, 1}\right.$ or $\left.V_{M, 2}\right)$, the initial end-expired alveolar volume $\left(V_{A}^{\prime}\right)$, the pulmonary blood flow $\left(\dot{Q}_{P}\right)$ and the fixed mixed venous return concentration $\left(C_{\bar{v}}\right)$, with the bounds in Table 1 used by the genetic algorithm. The FRC prediction was the sum of the dead space volumes and the mean end-expired alveolar volume across all breaths.

$\begin{array}{lll}\text { Model } 1 & \text { Model } 2 \quad \text { Model } 3\end{array}$

\begin{tabular}{|c|c|c|c|c|c|c|c|c|}
\hline & LB & UB & & LB & UB & & LB & UB \\
\hline \multirow{2}{*}{$V_{D}$} & \multirow{2}{*}{$5 \mathrm{ml}$} & \multirow{2}{*}{$400 \mathrm{ml}$} & $V_{M}$ & $5 \mathrm{ml}$ & $300 \mathrm{ml}$ & $V_{M, 1}$ & $5 \mathrm{ml}$ & $300 \mathrm{ml}$ \\
\hline & & & $V_{R}$ & $5 \mathrm{ml}$ & $300 \mathrm{ml}$ & $V_{M, 2}$ & $5 \mathrm{ml}$ & $300 \mathrm{ml}$ \\
\hline$V_{A}^{\prime}$ & 0.51 & 7.01 & $V_{\dot{A}}^{\prime}$ & 0.51 & 7.01 & $V_{\dot{A}}^{\prime}$ & 0.51 & 7.01 \\
\hline$\dot{Q}_{P}$ & $0.61 / \mathrm{min}$ & $181 / \mathrm{min}$ & $\dot{Q}_{P}$ & $0.61 / \mathrm{min}$ & $181 /$ min & $\dot{Q}_{P}$ & $0.61 / \mathrm{min}$ & $181 / \mathrm{min}$ \\
\hline$C_{\bar{v}}$ & $0 \%$ & $5 \%$ & $C_{\bar{v}}$ & $0 \%$ & $5 \%$ & $C_{\bar{v}}$ & $0 \%$ & $5 \%$ \\
\hline
\end{tabular}




\subsection{Participants}

In order to deliver a varying input, as required for spontaneous breathing or when using modern ventilators, the tracer gas needs to be delivered 'on the fly' (Clifton et al., 2013; Harrison, 2016). A sinusoidally varying inspired concentration was used (period $3 \mathrm{~min}$, amplitude $4 \%$ ).

All participants ( $n=17,10 \mathrm{M}$, mean age $23 \pm 3$ years, 2 smokers), with self-declared good health, had repeated measurements taken during a single session lasting approximately two hours. This was preceded or followed by a body plethysmograph (MasterScreen Body, Cardinal Health, USA) FRC measurement (mean $3.23 \pm 0.70 \mathrm{l}$ ). The order was randomly selected. The study was approved by the research ethics committee of the Medical Sciences Division, University of Oxford (Ref: MSD/IDREC/C1/2012/35) and written informed consent was obtained.

\subsection{Statistical Methods}

The coefficient of variation (CV) was used to assess repeatability of the results. The FRC results were also compared to the plethysmograph FRC. Deming regression was used as the plethysmograph predictions contain a similar amount of variation, so ordinary least squares would not provide reliable results (Bland and Altman, 1986; Cornbleet and Gochman, 1979; Wakkers et al., 1975). A measurement error ratio of 4 was used, based on the assumption that the approximate plethysmograph CV is $5 \%$ (Hankinson et al., 1998) and was $10 \%$ for model estimates.

A bootstrapping approach (Bruce, 2015) was used to determine the mean and standard deviation (SD) of several statistics. Where a repeated dataset for a subject is missing, the subject is excluded from that iteration. 100,000 bootstrap iterations were used, which resulted in a mean and SD consistent to two decimal points. In comparisons with the literature, the $95 \%$ confidence intervals (Cls) were estimated using the 2.5 and 97.5 percentiles and the standard error (SE) from the SD (Bruce, 2015; Pezzullo, 2013a, 2013b). Significance was determined using the two sample z-test (Bland, 2000). Where statistics were not given in the literature they are calculated from the mean and SD (Bland and Altman, 1986).

\section{Results}

The $\mathrm{CV}$ results (mean $\pm S D$ ) and the mean and SD of the bootstraps when the $F R C$ results are compared are shown in Table 2 and Table 3, respectively. The means are shown in Figure 2. As Model 3 performs best it was compared to the literature. Two papers were identified which made a similar comparison in healthy subjects of plethysmography with helium dilution and the LUFU device (Heinze et al. (2007), n=23, 35 \pm 10 years, no smoker details; Maisch et al. (2007), n=20, 27 \pm 2 years, 10 smokers). The results from these papers along with Model 3's results are detailed in Table 4. The p(C2017. This manuscript version is made available under the CC-BY-NC-ND 4.0 license http://creativecommons.org/licenses/by-nc-nd/4.0/ 


\begin{tabular}{l|cccccc} 
& $V_{M}$ or $V_{M, 1}$ & $V_{R}$ or $V_{M, 2}$ & $V_{D}$ & $V_{A}^{\prime}$ & FRC & $\dot{Q}_{P}$ \\
\hline Model 1 & - & - & $7.9 \pm 4.7$ & $13.3 \pm 5.5$ & $11.4 \pm 4.3$ & $27.7 \pm 18.4$ \\
Model 2 & $16.7 \pm 9.3$ & $14.8 \pm 10.7$ & $7.4 \pm 4.5$ & $12.1 \pm 6.3$ & $10.5 \pm 5.1$ & $26.9 \pm 23.0$ \\
Model 3 & $10.9 \pm 5.2$ & $8.8 \pm 3.6$ & $7.8 \pm 3.8$ & $8.4 \pm 2.8$ & $7.6 \pm 2.5$ & $20.0 \pm 12.1$ \\
& & &
\end{tabular}

\begin{tabular}{c|cccc|cc}
\multirow{2}{*}{ Model } & \multicolumn{5}{|c|}{ Regression Analysis } & \multicolumn{2}{c}{ Difference } \\
& Gradient & Intersect(I) & $\begin{array}{c}\text { SE of the } \\
\text { Estimate(l) }\end{array}$ & $\begin{array}{c}\text { Mid-point } \\
\text { Bias(I) }\end{array}$ & Mean(I) & SD(I) \\
\hline 1 & $1.12 \pm 0.14$ & $1.36 \pm 0.44$ & $0.37 \pm 0.04$ & $-0.91 \pm 0.09$ & $-0.95 \pm 0.08$ & $0.51 \pm 0.06$ \\
2 & $1.12 \pm 0.12$ & $-0.98 \pm 0.39$ & $0.31 \pm 0.05$ & $-0.54 \pm 0.08$ & $-0.58 \pm 0.08$ & $0.44 \pm 0.06$ \\
3 & $1.03 \pm 0.09$ & $-0.16 \pm 0.29$ & $0.21 \pm 0.03$ & $-0.05 \pm 0.07$ & $-0.06 \pm 0.06$ & $0.30 \pm 0.05$ \\
& Table 3-Bootstrap results when the recovered FRCs are compared to plethysmograph FRC.
\end{tabular}

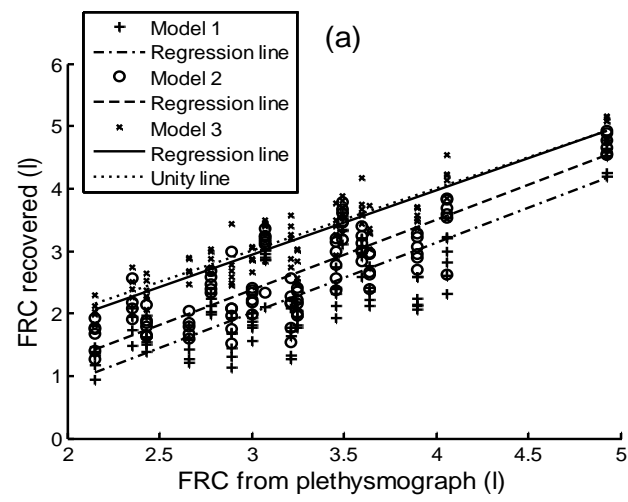

(c)

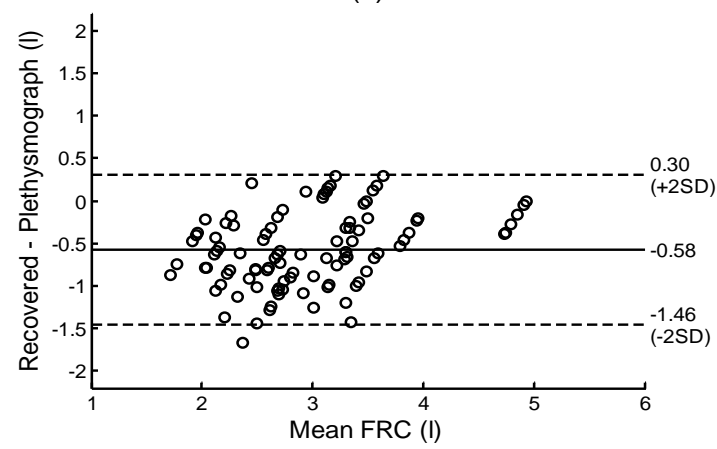

(b)

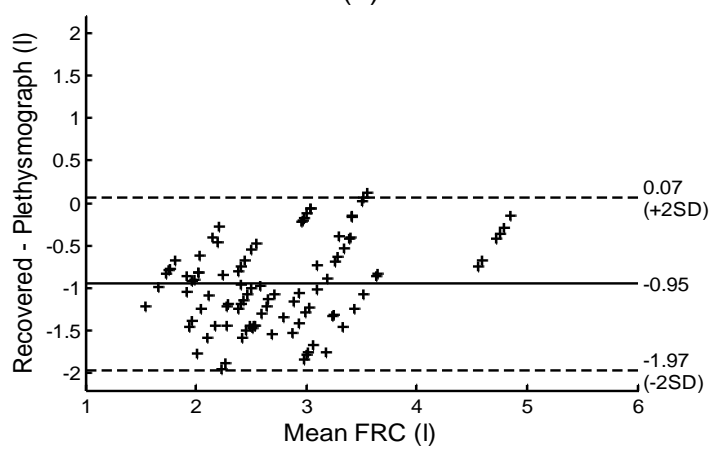

(d)

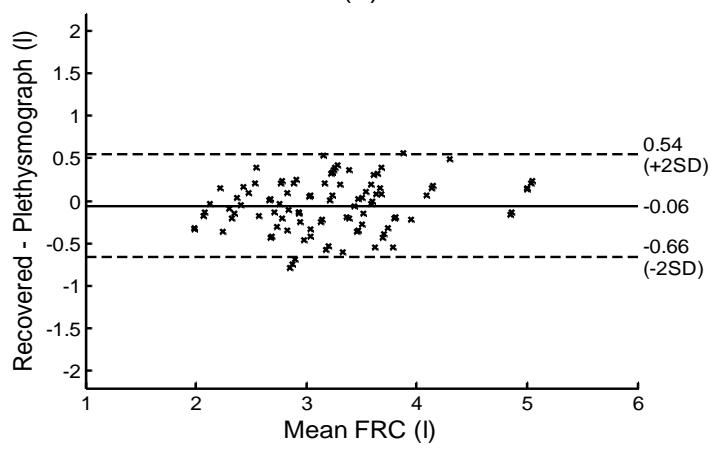

Figure 2 - Plots comparing the recovered FRC to plethysmograph FRC. (a) Scatter plot results for all models. Bland-Altman plots for (b) Model 1, (c) Model 2 and (d) Model 3.

\begin{tabular}{|c|c|c|c|c|c|c|}
\hline Method & Source & $\begin{array}{c}\text { Mean } \\
\text { Difference }\end{array}$ & $95 \% \mathrm{Cl}$ & $\begin{array}{l}\text { Limits of } \\
\text { Agreement }\end{array}$ & $\begin{array}{c}95 \% \mathrm{Cl} \\
\text { Lower Limit }\end{array}$ & $\begin{array}{c}95 \% \mathrm{Cl} \\
\text { Upper Limit }\end{array}$ \\
\hline Model 3 & & -0.06 & -0.18 to 0.07 & -0.66 to 0.54 & -0.86 to -0.42 & 0.32 to 0.75 \\
\hline \multirow{2}{*}{$\begin{array}{l}\text { Helium } \\
\text { Dilution }\end{array}$} & Heinze et al. & -0.3 & -0.5 to 0.1 & -1.3 to 0.7 & -1.7 to -0.9 & 0.3 to 1.0 \\
\hline & Maisch et al. & -0.03 & -0.23 to 0.17 & -0.89 to 0.83 & -1.24 to -0.54 & 0.48 to 1.18 \\
\hline \multirow{2}{*}{ LUFU } & Heinze et al. & -0.1 & -0.4 to 0.2 & -1.3 to 1.1 & -1.8 to -0.9 & 0.7 to 1.6 \\
\hline & Maisch et al. & -0.43 & -0.68 to -0.18 & -1.51 to 0.65 & -1.95 to -1.07 & 0.21 to 1.09 \\
\hline
\end{tabular}

(C2017. This manuscript version is made available under the CC-BY-NC-ND 4.0 license http://creativecommons.org/licenses/by-nc-nd/4.0/ 
Table 4 - Comparison of the bias and limits of agreement of the Model 3, helium dilution and LUFU methods when compared to plethysmography. Maisch et al. (2007) results are presented as given in the paper.

\begin{tabular}{ccc|ccc} 
Method & Source & Direction & $\begin{array}{c}\text { Mean } \\
\text { Difference }\end{array}$ & Lower Limit & Upper Limit \\
\hline \multirow{2}{*}{ Helium } & Heinze et al. & & 0.050 & $\mathbf{0 . 0 0 3}$ & 0.437 \\
dilution & \multirow{2}{*}{ Maisch et al } & As paper & 0.795 & 0.247 & 0.140 \\
& Inverted & 0.436 & 0.389 & 0.076 \\
\hline \multirow{2}{*}{ LUFU } & Heinze et al. & & 0.776 & $\mathbf{0 . 0 0 9}$ & $\mathbf{0 . 0 2 0}$ \\
& Maisch et al. & As paper & $\mathbf{0 . 0 0 7}$ & $<\mathbf{0 . 0 0 1}$ & 0.628 \\
& Inverted & $<0.001$ & 0.982 & $<\mathbf{0 . 0 0 1}$
\end{tabular}

Table 5 - p-values for the two sample z-test comparing the bias and the limits of agreement of Model 3 and those given in the literature.

values for the z-test are given in Table 5. As the direction of the difference is unknown for Maisch et al. (2007), the $p$-values of the inverted mean bias are also given.

\section{Discussion}

Model 3 performs better than the other two models. The CV data for the combined dead space volume are comparable across models. The $\mathrm{CV}$ data when lung compartments are combined are better than for the individual compartments that make up those volumes. This may signify that the proposed methods are not as capable of determining within which compartment the volume resides as they are in determining the total volume. However, as the compartments are only conceptual this is not important. The aim is only to model the dead space in such a way as to better determine the FRC, and potentially $V_{A}^{\prime}$, which are clinically significant parameters.

The CVs for $\dot{Q}_{P}$ are worse than for other parameters, which is likely to be because of more natural variation and the assumption of a fixed $C_{\bar{v}}$. Although a measure of $\dot{Q}_{P}$ could be clinically useful, some comparative value would be required to assess the predictions accuracy and the parameter is not the primary focus here. The results for $C_{\bar{v}}$ are not presented, as they will vary significantly between dataset depending on the manual equilibrium process and other factors unique to each dataset.

Model 3's more favourable results suggest that moving away from the traditional 'balloon on a straw' model to one that allows mixing within the dead space will result in a more accurate and precise measure of FRC and potentially other parameters. In reality, the human lung is not made of defined compartments, but has an ill-defined transition front from gas transport dominated by convection to gas transport dominated by diffusion, better matched to Model 3. Further investigation into the compartments and parameter estimation techniques used could improve 
results, as could simplifying more complex ventilation models, such as the Trumpet model (Hahn and Farmery, 2003).

The literature comparisons provide no evidence that the Model 3 method is any worse than either helium dilution or the LUFU device. The Model 3 method has a tighter confidence interval around zero difference. In the one situation where the mean difference is better (Maisch et al.'s (2007) helium dilution results) the p-value is above 0.4 for both directions. For the limits of agreement, the mean values for Model 3 are closer to zero than the limits of any other method. The one exception is the Maisch et al.'s (2007) LUFU lower limited when inverted, but the z-test result is insignificant and the opposite limit is $970 \mathrm{ml}$ worse. Both studies used a similar observation (but differently determined) to promote the use of the LUFU device.

There is no consistent evidence that Model 3's accuracy or precision is better than helium dilution. The mean error is on the bounds of being significantly better when compared to Heinze et al.'s (2007) (p-value 0.050). However, since the $z$-test is an approximation for low $n$ values and the study only gives results to one decimal point, no conclusions are drawn from that value here. Heinze et al.'s (2007) lower limit results suggest the precision of Model 3 is significantly better, but this is not supported by Maisch et al.'s (2007) data.

Maisch et al.'s (2007) mean difference results suggest Model 3 is significantly more accurate than the LUFU device, but this is not supported by Heinze et al. (2007). Both studies show Model 3 is significantly more precise than the LUFU device. For Maisch et al. (2007), the upper limit (lower limit when inverted) is not significantly worse, but one significantly different limit of agreement signifies the limits are significantly wider. In addition, the lack of significance is likely to be due to the mean difference being significantly more negative, which brings the upper limits close together. This fact and the very low $p$-value for the lower limit $(<0.001)$ supports the finding that Model 3 is significantly more precise.

It is acknowledged that this is not an extensive comparison with all the methods proposed in the literature, however the methods compared were chosen due to the availability of the required information and either their current clinical use or recent studies showing they have potential to improve the care of ventilated patients (Heinze et al., 2011, 2009; Karsten et al., 2011).

These comparisons have limitations. The methodological differences and the use of different plethysmographic instruments may have an effect along with differences between the cohorts. Where information is given the number of smokers is higher in the published studies. The cohort is 
younger than for all the other studies, but the average age is close to that of Maisch et al. (2007). All the results do, however, come from healthy subjects.

The fact that the same data were used to choose the model has the potential to produce more favourable results. Only three methods are detailed here, but other methods investigated are detailed in Harrison (2016). There are several factors that lower this risk. The number of different model/method combinations tried is relatively low and many of the models and methods are similar. Although there are only 17 subjects, 98 datasets are used in total. The models are based on what is considered to happen physiologically and they have shown similar results in separate data from a water-displacement bench lung (Harrison, 2016).

The way missing data are dealt with could influence results. The method used here has the potential to favour a subject with more datasets. Other methods of dealing with missing data could be used, but each has its own issues. Some alternative methods were investigated by Harrison (2016), with the same conclusions being reached.

Errors could be caused by the fixed Deming measurement error ratio. The ratio could be adjusted depending on the CV results of a given model. However, given that the plethysmography CV was based on a range from 3.5 to $6.8 \%$ (Hankinson et al., 1998) and the $10 \% \mathrm{CV}$ used is within one standard deviation of the mean in all cases, a fixed value was felt to be sufficient.

Improving the initial equilibrium process, potentially by automating it, could improve results. Further investigations, possibly using simulated data, could provide insight into how to bring the body to an equilibrium state in a timely manner. This could remove the requirement to estimate the $C_{\bar{v}}$ parameter with the mean sinewave concentration used instead. If this is not possible, having a repeatable process that brings the body closer to equilibrium may improve results. For ventilated patients the speed of the initial equilibrium process will be less of an issue.

It has been assumed that a lower mean difference is preferable, however historically, overestimates of FRC by plethysmography (or underestimates by other methods) of up to $10 \%$ have been observed (Brown et al., 1998; Cliff et al., 1999), but recent studies report less of a difference in healthy subjects (Heinze et al., 2007; Maisch et al., 2007; O’Donnell et al., 2010a, 2010b). The effect of nitrous oxide within the lung tissue is also unclear, if it acts as if it were within the lung it could potentially increase FRC predictions. Thus the expected difference between plethysmography and other methods is unknown and cannot be determined without an independent gold standard. This could affect the findings reached about the accuracies of these methods, however the mean 
differences reported for Model 3 are consistent with some of those observed elsewhere (Heinze et al., 2007; Maisch et al., 2007). The precision findings are not affected.

\section{Conclusion}

A dead space made up of two mixing compartments provided the best results. This suggests that a move away from the classic two-compartment 'balloon on a straw' model to a model that includes mixing within the airways, has the potential to better represent the gas concentration profile within the lung; thus improving the way the lung is modelled. This is likely to improve the information derived from lung ventilation models and so improve FRC or other predictions, which may lead to improved clinical decision making.

\section{Appendix A}

Model 1 assumes that no mixing or diffusion occurs within the dead space. Therefore during inspiration, assuming the dead space volume has already been inspired (i.e. $d_{D}<d_{0}$ ), the fractional concentration of a tracer gas that enters the alveolar compartment, $F_{I A}$, is:

$$
F_{I A}(t)=F_{I}\left(t-d_{D}\right),
$$

where $t$ is time, $F_{I}$ is the fractional concentration inspired at the mouth and $d_{D}$ is the time delay caused by the dead space compartment, which is dependent on the dead space volume, $V_{D}$. If the dead space volume has not been inspired (i.e. $d_{D}>d_{0}$ ), then the gas entering the alveolar compartment previously exited it:

$$
F_{I A}(t)=F_{A}\left(t-d_{0}\right)
$$

where $F_{A}$ is the fractional concentration of the alveolar compartment and $d_{0}$ is the time delay for gas to leave and then re-enter.

The total flow rate of air into the mouth, $\dot{V}$, is measured, allowing $d_{D}$ to be determined as the lowest value solution of the integral:

$$
\int_{t-d_{D}}^{t} \dot{V}(\Lambda) \mathrm{d} \Lambda=V_{D}
$$

Similarly, $d_{0}$ is the lowest value solution to the integral:

$$
\int_{t-d_{0}}^{t} \dot{V}(\Lambda) \mathrm{d} \Lambda=0
$$

During expiration the expired fractional concentration, $F_{E}$, can be determined in a similar way:

$$
\begin{array}{ll}
F_{E}(t)=F_{A}\left(t-d_{D}\right) & \text { if } d_{D}<d_{0} \\
F_{E}(t)=F_{I}\left(t-d_{0}\right) & \text { if } d_{D}>d_{0},
\end{array}
$$

where the time delays are determined from the following integrals: 


$$
\begin{gathered}
\int_{t-d_{D}}^{t} \dot{V}(\Lambda) \mathrm{d} \Lambda=-V_{D} \\
\int_{t-d_{0}}^{t} \dot{V}(\Lambda) \mathrm{d} \Lambda=0 .
\end{gathered}
$$

Model 2 includes an additional mixing compartment at the mouth. Air entering this compartment fully mixes with the air already in it, with the compartment's mass balance equations being:

$$
\begin{aligned}
V_{M} \frac{\mathrm{d} F_{M}(t)}{\mathrm{d} t}=\dot{V}(t) \cdot\left(F_{I}(t)-F_{M}(t)\right) & & \text { for inspiration } \\
V_{M} \frac{\mathrm{d} F_{M}(t)}{\mathrm{d} t}=\dot{V}(t) \cdot\left(F_{M}(t)-F_{E R}(t)\right) & & \text { for expiration, }
\end{aligned}
$$

where $F_{M}$ is the fractional concentration of tracer gas in the mixing compartment, $V_{M}$ is the fixed mixing compartment volume and $F_{E R}$ is the fractional concentration expired from the transitory compartment. Flow is negative during expiration, hence $F_{M}$ is positive and $F_{E R}$ is negative in the Equation A.1.

The equations for the transitory compartment are similar to that of the dead space Model 1. During inspiration:

$$
\begin{array}{ll}
F_{I A}(t)=F_{M}\left(t-d_{R}\right) & \text { if } d_{R}<d_{0} \\
F_{I A}(t)=F_{A}\left(t-d_{0}\right) & \text { if } d_{R}>d_{0},
\end{array}
$$

with the delays being the lowest value solutions of:

$$
\begin{aligned}
& \int_{t-d_{R}}^{t} \dot{V}(\Lambda) \mathrm{d} \Lambda=V_{R} \\
& \int_{t-d_{0}}^{t} \dot{V}(\Lambda) \mathrm{d} \Lambda=0,
\end{aligned}
$$

where $V_{R}$ is the transitory compartment volume and $d_{R}$ is the delay induced by that volume. During expiration:

$$
\begin{array}{ll}
F_{E R}(t)=F_{A}\left(t-d_{R}\right) & \text { if } d_{R}<d_{0} \\
F_{E R}(t)=F_{M}\left(t-d_{0}\right) & \text { if } d_{R}>d_{0},
\end{array}
$$

with the delays being the lowest value solutions of:

$$
\begin{gathered}
\int_{t-d_{R}}^{t} \dot{V}(\Lambda) \mathrm{d} \Lambda=-V_{R} \\
\int_{t-d_{0}}^{t} \dot{V}(\Lambda) \mathrm{d} \Lambda=0
\end{gathered}
$$

$F_{E}$ is equal to $F_{M}$ during expiration.

Model 3 assumes two fixed volume mixing compartments, with the following mass balance equations: 


$$
\begin{aligned}
& V_{M, 1} \frac{\mathrm{d} F_{M, 1}(t)}{\mathrm{d} t}=\dot{V}(t) \cdot\left(F_{I}(t)-F_{M, 1}(t)\right) \\
& V_{M, 2} \frac{\mathrm{d} F_{M, 2}(t)}{\mathrm{d} t}=\dot{V}(t) \cdot\left(F_{M, 1}(t)-F_{M, 2}(t)\right) \\
& V_{M, 1} \frac{\mathrm{d} F_{M, 1}(t)}{\mathrm{d} t}=\dot{V}(t) \cdot\left(F_{M, 1}(t)-F_{M, 2}(t)\right) \\
& V_{M, 2} \frac{\mathrm{d} F_{M, 2}(t)}{\mathrm{d} t}=\dot{V}(t) \cdot\left(F_{M, 2}(t)-F_{A}(t)\right)
\end{aligned}
$$

where the numerical subscripts signify the two mixing compartments, starting from the mouth.

During inspiration $F_{I A}(t)=F_{M, 2}(t)$ and during expiration $F_{E}(t)=F_{M, 1}(t)$.

The alveolar compartment is modelled in the same way throughout. The mass of the tracer gas within the alveoli compartment is governed by two mass balance equations (similar to those used in previous models (Gavaghan and Hahn, 1996; Hahn and Farmery, 2003)):

$$
\begin{array}{ll}
\frac{\mathrm{d}}{\mathrm{d} t}\left(V_{A}(t) \cdot F_{A}(t)\right)=\frac{\mathrm{d} V_{A}(t)}{\mathrm{d} t} F_{I A}(t)+\dot{Q}_{P}\left(C_{\bar{v}}(t)-C_{a}(t)\right) & \text { for inspiration } \\
\frac{\mathrm{d}}{\mathrm{d} t}\left(V_{A}(t) \cdot F_{A}(t)\right)=\frac{\mathrm{d} V_{A}(t)}{\mathrm{d} t} F_{A}(t)+\dot{Q}_{P}\left(C_{\bar{v}}(t)-C_{a}(t)\right) & \text { for expiration, }
\end{array}
$$

where $V_{A}$ is the alveolar compartment volume, $\dot{Q}_{P}$ is the pulmonary blood flow rate and $C_{a}$ and $C_{\bar{v}}$ are the concentration (gas volume/liquid volume) of tracer gas in the end-capillary and mixed venous blood.

The dead space volume is fixed and the change in $V_{A}$ due to the exchange of the tracer gas with the body is assumed to be negligible (as shown to be reasonable elsewhere (Barton et al., 1988a, 1988b; Harrison, 2016)), so:

$$
\frac{\mathrm{d} V_{A}(t)}{\mathrm{d} t}=\dot{V}(t)
$$

Equilibrium is assumed to be reached within the lung (an assumption made in previous models (Gavaghan and Hahn, 1996; Hahn et al., 1993; Hahn and Farmery, 2003)), thus:

$$
C_{a}(t)=\lambda \cdot F_{A}(t),
$$

where $\lambda$ is the blood-gas partition coefficient. Finally $C_{\bar{v}}$ is assumed to be constant, as described in the main text. Combining these assumptions Equation A.2 and A.3 become:

$$
\begin{array}{llrl}
\frac{\mathrm{d}}{\mathrm{d} t}\left(V_{A}(t) \cdot F_{A}(t)\right) & =\dot{V}(t) \cdot F_{I A}(t)+\dot{Q}_{P}\left(C_{\bar{v}}-\lambda \cdot F_{A}(t)\right) & & \text { for inspiration } \\
\frac{\mathrm{d}}{\mathrm{d} t}\left(V_{A}(t) \cdot F_{A}(t)\right) & =\dot{V}(t) \cdot F_{A}(t)+\dot{Q}_{P}\left(C_{\bar{v}}-\lambda \cdot F_{A}(t)\right) & & \text { for expiration . }
\end{array}
$$




\section{Acknowledgments}

Chris D. Harrison acknowledges the support of the RCUK Digital Economy Programme grant number EP/G036861/1 (Oxford Centre for Doctoral Training in Healthcare Innovation). The authors would like to acknowledge the support of the National Institute of Health Research i4i grant number II-LA0214-0005 in the development of the gas delivery device, the use of the University of Oxford Advanced Research Computing (ARC) facility (http://dx.doi.org/10.5281/zenodo.22558) and the valuable input of Clive E. W. Hahn and Linda J. Harrison.

\section{References}

Arieli, R., 2010. Mass spectrometer for respiratory research. Respir. Physiol. Neurobiol. 170, 183-4. Barton, S.A., Black, A.M.S., Hahn, C.E.W., 1988a. Dynamic models and solutions for evaluating ventilation, perfusion, and mass transfer in the lung - Part I: The models. IEEE Trans. Biomed. Eng. 35, 450-457.

Barton, S.A., Black, A.M.S., Hahn, C.E.W., 1988b. Dynamic models and solutions for evaluating ventilation, perfusion, and mass transfer in the lung - Part II: Analog solutions. IEEE Trans. Biomed. Eng. 35, 458-465.

Bates, J.H., Prisk, G.K., Tanner, T.E., McKinnon, A.E., 1983. Correcting for the dynamic response of a respiratory mass spectrometer. J. Appl. Physiol. 55, 1015-22.

Belegundu, A.D., Chandrupatla, T.R., 2011. Optimization Concepts and Applications in Engineering. Cambridge University Press.

Bland, J.M., Altman, D.G., 1986. Statistical methods for assessing agreement between two methods of clinical measurement. Lancet 327, 307-310.

Bland, M., 2000. An Introduction to Medical Statistics, 3rd ed. Oxford University Press, Oxford. Brewer, L.M., Orr, J.A., Sherman, M.R., Fulcher, E.H., Markewitz, B.A., 2011. Measurement of functional residual capacity by modified multiple breath nitrogen washout for spontaneously breathing and mechanically ventilated patients. Br. J. Anaesth. 107, 796-805.

Brown, R., Leith, D.E., Enright, P.L., 1998. Multiple breath helium dilution measurement of lung 
volumes in adults. Eur. Respir. J. 11, 246-55.

Bruce, P.C., 2015. Introductory Statistics and Analytics: A Resampling Perspective. Wiley.

Cliff, I.J., Evans, A.H., Pantin, C.F.A., Baldwin, D.R., 1999. Comparison of two new methods for the measurement of lung volumes with two standard methods. Thorax 54, 329-333.

Clifton, L.A., Clifton, D.A., Hahn, C.E.W., Farmery, A.D., 2013. Assessment of lung function using a non-invasive oscillating gas-forcing technique. Respir. Physiol. Neurobiol. 189, 174-82.

Cornbleet, P.J., Gochman, N., 1979. Incorrect least-squares regression coefficients in methodcomparison analysis. Clin. Chem. 25, 432-8.

Cortes, G.A., Marini, J.J., 2013. Two steps forward in bedside monitoring of lung mechanics: transpulmonary pressure and lung volume. Crit. Care 17, 219.

Dushianthan, A., Grocott, M.P.W., Postle, A.D., Cusack, R., 2011. Acute respiratory distress syndrome and acute lung injury. Postgrad. Med. J. 87, 612-22.

Farmery, A.D., 2008. Interrogation of the Cardiopulmonary System with Inspired Gas Tension Sinusoids. University of London.

Gajic, O., Dara, S.I., Mendez, J.L., Adesanya, A.O., Festic, E., Caples, S.M., Rana, R., St Sauver, J.L., Lymp, J.F., Afessa, B., Hubmayr, R.D., 2004. Ventilator-associated lung injury in patients without acute lung injury at the onset of mechanical ventilation. Crit. Care Med. 32, 1817-24.

Gavaghan, D.J., Hahn, C.E.W., 1996. A tidal breathing model of the forced inspired inert gas sinewave technique. Respir. Physiol. 106, 209-221.

Gavaghan, D.J., Hahn, C.E.W., 1995. A mathematical evaluation of the alveolar amplitude response technique. Respir. Physiol. 102, 105-120.

Gothard, J.W.W., Busst, C.M., Branthwaite, M.A., Davies, N.J.H., Denison, D.M., 1980. Applications of respiratory mass spectrometry to intensive care. Anaesthesia 35, 890-895.

Hahn, C.E.W., 1996. Oxygen respiratory gas analysis by sine-wave measurement: a theoretical model. J. Appl. Physiol. 81, 985-97.

C2017. This manuscript version is made available under the CC-BY-NC-ND 4.0 license http://creativecommons.org/licenses/by-nc-nd/4.0/ 
Hahn, C.E.W., Black, A.M.S., Barton, S.A., Scott, I., 1993. Gas exchange in a three-compartment lung model analyzed by forcing sinusoids of N2O. J. Appl. Physiol. 75, 1863-1876.

Hahn, C.E.W., Farmery, A.D., 2003. Gas exchange modelling: No more gills, please. Br. J. Anaesth. 91, 2-15.

Hankinson, J., Stocks, J., Peslin, R., 1998. Reproducibility of lung volume measurements. Eur. Respir. J. $11,787-790$.

Harrison, C.D., 2016. Methods for Determining Lung Function from Tracer Gas Concentrations. University of Oxford.

Hedenstierna, G., 1993. The recording of FRC - is it of importance and can it be made simple? Intensive Care Med. 19, 365-366.

Heinze, H., Eichler, W., Karsten, J., Sedemund-Adib, B., Heringlake, M., Meier, T., 2011. Functional residual capacity-guided alveolar recruitment strategy after endotracheal suctioning in cardiac surgery patients. Crit. Care Med. 39, 1042-9.

Heinze, H., Schaaf, B., Grefer, J., Klotz, K., Eichler, W., 2007. The accuracy of the oxygen washout technique for functional residual capacity assessment during spontaneous breathing. Anesth. Analg. 104, 598-604.

Heinze, H., Sedemund-Adib, B., Heringlake, M., Meier, T., Eichler, W., 2009. Changes in functional residual capacity during weaning from mechanical ventilation: a pilot study. Anesth. Analg. 108, $911-5$

Horsley, A.R., Macleod, K., Gupta, R., Goddard, N., Bell, N., 2014. Enhanced photoacoustic gas analyser response time and impact on accuracy at fast ventilation rates during multiple breath washout. PLoS One 9, e98487.

Karsten, J., Meier, T., Heinze, H., 2011. Bedside-measurements of electrical impedance tomography and functional residual capacity during positioning therapy in a case of acute respiratory failure. Appl. Cardiopulm. Pathophysiol. 15, 81-86.

(C2017. This manuscript version is made available under the CC-BY-NC-ND 4.0 license http://creativecommons.org/licenses/by-nc-nd/4.0/ 
Maisch, S., Boehm, S.H., Weismann, D., Reissmann, H., Beckmann, M., Fuellekrug, B., Meyer, A., Schulte Am Esch, J., 2007. Determination of functional residual capacity by oxygen washinwashout: a validation study. Intensive Care Med. 33, 912-6.

Matlab R2014a documentation [WWW Document], 2014. URL http://www.mathworks.co.uk/help/matlab/ (accessed 9.11.14).

Miller, R.R., Macintyre, N.R., Hite, R.D., Truwit, J.D., Brower, R.G., Morris, A.H., 2012. Point: should positive end-expiratory pressure in patients with ARDS be set on oxygenation? Yes. Chest 141, 1379-82.

Mitchell, R.R., Wilson, R.M., Holzapfel, L., Benis, A.M., Sierra, D., Osborn, J.J., 1982. Oxygen wash-in method for monitoring functional residual capacity. Crit. Care Med. 10, 529-33.

O’Donnell, C.R., Bankier, A.A., Stiebellehner, L., Reilly, J.J., Brown, R., Loring, S.H., 2010a. Comparison of plethysmographic and helium dilution lung volumes: Which is best for COPD? Chest 137, 1108-15.

O’Donnell, C.R., Bankier, A.A., Stiebellehner, L., Reilly, J.J., Brown, R., Loring, S.H., 2010b. How To Measure Lung Volume?: Response. Chest 138, 1281-1282.

Olegård, C., Söndergaard, S., Houltz, E., Lundin, S., Stenqvist, O., 2005. Estimation of functional residual capacity at the bedside using standard monitoring equipment: a modified nitrogen washout/washin technique requiring a small change of the inspired oxygen fraction. Anesth. Analg. 101, 206-12.

Pezzullo, J., 2013a. Biostatistics For Dummies. John Wiley \& Sons, Somerset, NJ, USA.

Pezzullo, J., 2013b. The Bootstrap Method for Standard Errors and Confidence Intervals [WWW Document]. Biostat. Dummies Extras. URL www.dummies.com/extras/biostatistics (accessed 1.12.15).

Rouby, J.-J., Arbelot, C., Brisson, H., Lu, Q., Bouhemad, B., 2013. Measurement of alveolar recruitment at the bedside: the beginning of a new era in respiratory monitoring? Respir. Care 
$58,539-42$.

Schmidt, G.A., 2012. Counterpoint: should positive end-expiratory pressure in patients with ARDS be set based on oxygenation? No. Chest 141, 1382-4.

Sivan, Y., Deakers, T.W., Newth, C.J.L., 1990. An Automated Bedside Method for Measuring Functional Residual Capacity by N2 Washout in Mechanically Ventilated Children. Pediatr. Res. $28,446-450$.

Soni, N., Williams, P., 2008. Positive pressure ventilation: what is the real cost? Br. J. Anaesth. 101, 446-457.

Wakkers, P.J.M., Hellendoorn, H.B.A., De Weegh, G.J.O., Heerspink, W., 1975. Applications of statistics in clinical chemistry. Clin. Chim. acta 64, 173-184.

Weismann, D., Reissmann, H., Maisch, S., Füllekrug, B., Schulte, J., 2006. Monitoring of functional residual capacity by an oxygen washin/washout; technical description and evaluation. J. Clin. Monit. Comput. 20, 251-60.

Williams, E.M., Aspel, J.B., Burrough, S.M., Ryder, W.A., Sainsbury, M.C., Sutton, L., Xiong, L., Black, A.M.S., Hahn, C.E.W., 1994. Assessment of cardiorespiratory function using oscillating inert gas forcing signals. J. Appl. Physiol. 76, 2130-2139.

Williams, E.M., Hamilton, R.M., Sutton, L., Viale, J.P., Hahn, C.E.W., 1997. Alveolar and dead space volume measured by oscillations of inspired oxygen in awake adults. Am. J. Respir. Crit. Care Med. 156, 1834-9. 